\title{
THE LEVEL OF RUMINATIVE THOUGHT AND ALEXITHYMIA OF PEOPLE IN THE COVID-19 PANDEMIC PROCESS
}

\author{
Elif Yıldırım Ayaz ${ }^{1}$ \& Berna Dincer ${ }^{2}$ \\ ${ }^{1}$ Sultan Abdülhamid Han Training and Research Hospital, Department of Internal Medicine, Istanbul, Turkey \\ ${ }^{2}$ Istanbul Medeniyet University, Faculty of Health Sciences, Department of Internal Medical Nursing, İstanbul, Turkey \\ received: 14.11.2020; \\ revised: 27.1.2021; \\ accepted: 20.2 .2021
}

\section{SUMMARY}

Objective: The COVID-19 pandemic process caused many physiological and psychological effects on individuals. This study aims to examine the ruminative thinking and alexithymia levels of people in the COVID-19 pandemic process.

Methods: The descriptive, cross-sectional, and the correlational designed study was conducted with 852 people in IstanbuATurkey during the COVID-19 pandemic process between March and May 2020. The data of the research was collected with the Sociodemographic Form Toronto Alexithymia Scale and Ruminative Thought Style Questionnaire.

Results: It was found that the average of ruminative thought score of the people was $92.49 \pm 19.89$ and the alexithymia score average was 71.76 \pm 13.70. A positive and significant relationship was found between the Ruminative Thought Style Questionnaire and the Toronto Alexithymia Scale and subscale scores $(p<0.05)$. According to the results, ruminative thinking levels were affected by $12 \%$ alexithymia level and $9 \%$ time spent on conversation. A statistically significant relationship was found between rumination, alexithymia, and its sub-dimensions and the number of times people spend for conversation during the day and the number of people they live with ( $p<0.05)$. It was determined that those living with family/friends were lower than those who were alone, and those with good communication in relationships had lower rumination and alexithymia $(p<0.05)$.

Conclusion: Care should be taken against alexithymia and rumination during the COVID-19 pandemic process, and attention should be given to interpersonal relationships, conversation, and communication in the quarantine process.

Key words: COVID-19 - alexithymia - ruminative thought-pandemics - public health

$$
* \quad * \quad * \quad * *
$$

\section{INTRODUCTION}

COVID-19 disease, which became a current issue with cases of pneumonia of unknown etiology on 31 December 2019 in Wuhan City, Hubei Province, China, has spread rapidly to the world. As early as March 2020, the pandemic in China slowed down, while COVID-19 cases and associated deaths increased in Iran, the Republic of Korea (South Korea) Italy, Spain, and the United States. As of 26 January 2021, there were $100,556,969$ confirmed cases in the world, 72,512,429 people recovering, while $2,157,787$ patients died due to the virus (Worldometers 2020).

Since the date of the first virus-related (2019-nCoV) case notification, social, economic, and political arrangements have been made for preventive purposes both in Turkey and in many countries worldwide (WHO 2020). Within the scope of these measures, social isolation and quarantine practices restricted people's social lives (Jakovljevic et al. 2020, Marčinko et al. 2020, Ćosić et al. 2020).

The COVID-19 pandemic process has had many physiological and psychological effects on individuals (Wang et al. 2020). The rapid launch of the quarantine application caused a radical change in the lifestyle of the population (Aktug et al. 2020, Jakovljevic et al. 2020, Marčinko et al. 2020, Ćosić et al. 2020). Mass social isolation can result in problems with mental health in most people. Psychological effects such as emotional fluctuations, depression, stress, sleep disorders, irritability, and anger are among the findings frequently seen in the quarantine process (Brooks et al. 2020). Uncertainty of how long the process will take and what it can lead to, the fear that the disease will infect the person or his family, the unsafe assessment of the place of living in terms of infection creates fear and stress in people, causing anxiety and depression symptoms (Brooks et al. 2020, (Jakovljevic et al. 2020, Marčinko et al. 2020). In a study conducted with 4872 participants over the age of 18 in Wuhan, it was found that during the COVID-19 outbreak, depression was $48.3 \%$, anxiety was $22.6 \%$, and depression and anxiety were $19.4 \%$ (Gao et al. 2020). Rumination and alexithymia occurring in situations such as anxiety, depression, and stress can be seen in the quarantine process.

When individuals experience difficulties or upset, emotional states can respond in a variety of ways. One of these is rumination. It is repetitive and passive thinking of situations that cause rumination, stress, and anxiety, which are thought to play a role in the formation and maintenance of many psychopathologies (Papageorgiou \& Wells 2003). Rumination is continuously thinking about the causes and consequences of the negative emotional situation, instead of finding a solution to the problem that a person experiences (Smith \& Alloy 2009). Although the tendency towards 
rumination shows personal differences, studies indicate that people tend to think more ruminative in case of trouble, and this causes depressive disorders (NolenHoeksema et al. 2007).

In recent studies, it has been reported that emotional disorders and psychological problems are observed in the COVID-19 outbreak (Siyu et al. 2020, Huang et al. 2020, Sun et al. 2020). Another psychological condition experienced in the pandemic process is alexithymia (Tang et al. 2020). Also called emotional deafness, alexithymia is psychopathology characterized by difficulty in understanding, defining, and expressing people's feelings (Beyens et al. 2016). Wanjie Tang et al. in their study, detected severe alexithymia in individuals during the COVID-19 pandemic process (Tang et al. 2020).

Alexithymia consists of three conditions: difficulty identifying feelings (DIF), difficulty describing feelings (DDF), and externally oriented thinking (EOT) (Hendryx et al. 1991, Taylor 1984, Sifneos 1991). Individuals with alexithymia tend to think tangibly and have symptoms such as difficulty in distinguishing physical sensations from emotional sensations and decreased ability to dream (Caretti 2011). Individuals with severe alexithymia cannot cognitively notice and express their feelings (Taylor 1994). Previous studies have found that trauma is related to alexithymia (Westwood et al. 2017, Karsikaya et al. 2013).

The change in the social life, relationships, and psychosocial status of individuals due to the quarantine process poses a risk for ruminative thought and alexithymia. This is an important issue that needs to be investigated, as it can lead to a negative impact on the daily lives of individuals and to deteriorate interpersonal communication and relationships. There has been no study found evaluating the levels of individuals' ruminative thinking and alexithymia in the COVID-19 pandemic process in the literature. However, there is no study investigating alexithymia and rumination in individuals.

This study was carried out to investigate the levels of ruminative thinking and alexithymia of individuals during the COVID-19 pandemic process.

\section{Purpose of the Study}

In this study, ruminative thinking and alexithymia levels of people and their relationship between was evaluated, factors affecting ruminative thinking and alexithymia levels were investigated.

\section{METHODS}

\section{Study Design}

This study was conducted in descriptive, crosssectional, and correlational design types between March and May 2020 with people in İstanbul\Turkey during the COVID-19 pandemic process.

\section{Sample and Participants}

The study included individuals who are 18 years or older, volunteering to participate in the research, have no communication problems, are literate, and live in İstanbullTurkey during the COVID-19 pandemic process. The city of İstanbul was preferred due to the presence of people from all regions of Turkey, its highest population density, and the highest number of COVID-19 cases. The sample size was calculated to achieve a power of $95 \%$ at a 0.05 level of significance. The power calculation indicated that the required sample size was 850 person. 852 people participated in the study. Since 17 people were diagnosed with psychiatric illness and 12 did not fill out the questionnaire fully, they were excluded from the study. The study was completed with 823 people.

\section{Procedure}

Approval was taken from the University's Ethics Committee (approval number: 2020\0210) before the study commenced. After informing the persons about the study, persons who agreed to participate read and signed online the consent forms. Participants were informed about the study objectives, procedures, and data confidentiality, and that participation was voluntary and they could leave the research at any time. Online permission was taken from the university where the study was conducted. The study was conducted in compliance with the "Ethical principles for medical research involving human subjects" of the Helsinki Declaration. Data collection forms were created using Survey Monkey (2005 SurveyMonkey.com), which provides electronic self-control and facilitates data collection and tracking by preventing multiple entries from the same person. (last data entry: 10\06\.2020). Confidentiality was guaranteed by completely disabling electronic records and IP address records.

\section{Data Collection}

The data of the research was collected with the Sociodemographic Form Toronto Alexithymia Scale and Ruminative Thought Style Questionnaire.

Sociodemographic Form: In the form developed by the researchers, there are 14 questions including questions such as the participants' age, gender, marital status, educational status, income level, pre-COVID-19 pandemic status, smoking habits, change in smoking habits during the pandemic period, whether he/she or a relative has had/or having COVID-19 disease, time spent for conversation during the day, communication in relationships, people whom they live with during the quarantine process.

Toronto Alexithymia Scale (TAS-20): The scale developed by Bagby et al. (1986) consists of 20 questions. Turkish validity reliability was done by Gulec et al. (2010). This scale evaluates the status of alexithymia, which is defined as the lack of self-emotion and 
excitement. The scale containing the answers "Never", "Rarely", "Sometimes", "Often" and "Always" is of 5point Likert type. The scale has a subscale. The Difficulty in Recognizing Emotions subscale consists of seven items (items 1, 3, 6, 7, 9, 13, and 14), which is defined as difficulty in identifying emotions and distinguishing them from bodily sensations accompanying emotional arousal. In addition, the Difficulty in Speaking Emotions subscale consists of five items (items 2, 4, 11, 12 and 17), which is defined as a difficulty in transferring emotions to others. A high score on the scale indicates the difficulty of expressing feelings.

The reliability coefficients of the subscales are 0.82 , 0.75 and 0.72 , respectively. In this study, we found the reliability coefficients as $0.85,0.80$ and 0.74 , respectively. The scoring is done by summing up the points of the items. The lowest score that can be obtained from the scale is 20, and the highest score is 100 . High scores indicate high alexithymia levels.

Ruminative Thought Style Questionnaire: The scale developed by Brinker and Dozois (2009) is used to evaluate ruminative ways of thinking. The scale consists of 20 items and has a 7-point Likert type. Participants mark a score that suits themselves to a degree between 7 (describes me very well) and 1 (doesn't describe me at all). The high scores obtained from the scale mean that ruminative thinking is high. Turkish validity reliability of the scale was performed by Karatepe (2013). As a result of the Scree-plot analysis conducted in the construct validity study, the scale was found to have a single factor structure and this factor explained $64.43 \%$ of the total variance. Principal components analysis also supports this finding. In the reliability study, the internal consistency of the scale was found high with correlation analysis $(\alpha=0.91)$. The results showed that the scale is valid and reliable. In this study, Cronbach Alpha value was found at 0.89 .

\section{Data Analysis}

The frequency, percentage, mean, and standard deviation of the data were analyzed using SPSS (Statistical Package for Social Sciences, Chicago, Illinois) version 25.0. The conformity of the data to the normal distribution was evaluated with the Kolmogorov-Smirnov test. According to the non-normal distribution of the data, Mann-Whitney U, and Kruskal-Wallis (posthoc Bonferroni) tests were used to compare groups. The Pearson correlation test was used to evaluate the variation of the variables. The effects of Variables that Affect Ruminative Thought were evaluated using multiple regression analysis. The results were assessed at a $95 \%$ confidence interval and $\mathrm{p}<0.05$ significance level.

\section{RESULTS}

The average age of the participants in the study is $49.9 \pm 14.16,54.4 \%$ is male and the majority $(72.3 \%)$ is married. $63.7 \%$ of their families or relatives were infected with SARS-COV-2, and 79.1\% worked before the pandemic process. $35.7 \%$ of people smoke, and $20.3 \%$ of them reported increased smoking during the pandemic process. The average daily cigarette consumption of smokers is $14.24 \pm 5.92$ (Table 1).

\section{Ruminative thinking and Alexithymia scores}

When the ruminative score average $(92.49 \pm 19.89)$ and alexithymia score average $(71.76 \pm 13.70)$ of the individuals were examined, it was found that both of them were above the upper limit value (Table 2).

Table 1. Participants Characteristics $(\mathrm{N}=823)$

\begin{tabular}{|c|c|c|}
\hline Characteristic & $\mathrm{n}$ & $\%$ \\
\hline \multicolumn{3}{|l|}{ Gender } \\
\hline Female & 375 & 45.6 \\
\hline Male & 448 & 54.4 \\
\hline Min: 19 Max:75 & $\bar{X}=49.9 \pm$ & 14.16 \\
\hline \multicolumn{3}{|l|}{ Marital Status } \\
\hline Married & 529 & 72.3 \\
\hline Single & 228 & 27.7 \\
\hline \multicolumn{3}{|l|}{ Educational Background } \\
\hline Primary School & 36 & 4.4 \\
\hline Secondary School & 266 & 32.3 \\
\hline High School & 204 & 24.8 \\
\hline University & 214 & 26.0 \\
\hline Graduate $\backslash$ Doctorate & 103 & 12.5 \\
\hline \multicolumn{3}{|l|}{ Income Level } \\
\hline Good & 164 & 19.9 \\
\hline $\mathrm{Bad}$ & 532 & 64.6 \\
\hline Medium & 127 & 15.4 \\
\hline \multicolumn{3}{|l|}{ Infected COVID-19 } \\
\hline Him/Herself & 37 & 4.5 \\
\hline Family $\backslash$ Relative & 524 & 63.7 \\
\hline Nobody & 262 & 31.8 \\
\hline \multicolumn{3}{|c|}{ Working status before the COVID-19 Process } \\
\hline Working \student & 651 & 79.1 \\
\hline Unemployed & 172 & 20.9 \\
\hline \multicolumn{3}{|l|}{ Smoking } \\
\hline Yes & 294 & 35.7 \\
\hline No & 529 & 64.3 \\
\hline
\end{tabular}

Daily smoking amount Min: 0; Max:45; $\bar{X}=14.24 \pm 5.92$

Change in smoking in the COVID-19 process ( $\mathrm{n}: 294)$

$\begin{array}{lrr}\text { Yes, it increased } & 167 & 20.3 \\ \text { No it has not changed } & 100 & 12.2 \\ \text { Yes, it decreased } & 27 & 3.3\end{array}$

Time spent on conversation throughout the day Min: 1 Max:13 $\overline{\mathrm{X}}=5.85 \pm 1.86$

Communication in relationships

$\begin{array}{lll}\text { Good } & 320 & 38.9 \\ \text { Poor } & 280 & 34.0 \\ \text { No Answer } & 223 & 27.1 \\ \text { Who he/she lives with } & & \\ \text { Alone } & 283 & 34.4 \\ \text { Familylfriend } & 540 & 65.6\end{array}$

Number of people living together

$$
\text { Min: } 0 \text { Max:8 } \bar{X}=4.2 \pm 1.16
$$

Min: minimum value; Max: maximum value;

Sd: Standard deviation 
Table 2. The relationship between ruminative thinking and alexithymia level of people $(\mathrm{N}=823)$

\begin{tabular}{lccc}
\hline \multirow{2}{*}{ Scales } & Scale Total Score & Ruminative Thinking Scale \\
& $\mathrm{X} \pm \mathrm{Sd}(\min -\max )$ & $\mathrm{r}^{\mathrm{a}}$ & $\mathrm{p}$ \\
\hline Ruminative Thought Style Questinnaire & $92.49 \pm 19.89(10-140)$ & 1.000 & - \\
Toronto Alexithymia Scale & $71.76 \pm 13.70(10-100)$ & 0.094 & 0.007 \\
Difficulty in recognizing feelings & $24.50 \pm 5.21(9-35)$ & 0.081 & 0.020 \\
Difficulty in expressing feelings & $17.72 \pm 4.13(7-25)$ & 0.082 & 0.019 \\
Expressive thought & $29.53 \pm 5.74(12-41)$ & 0.091 & 0.009 \\
\hline
\end{tabular}

$\mathrm{p}<0.05 ; \mathrm{r}^{\mathrm{a}}$ Pearson correlation test was used

Table 3. Multiple regression analysis results of variables that have an impact on people's ruminative thoughts $(\mathrm{N}=823)$

\begin{tabular}{lcccccrrr} 
Independent Variables & $\mathrm{B}$ & $\begin{array}{c}\text { Standard } \\
\text { Error }\end{array}$ & $\begin{array}{c}\text { Standard } \\
\text { Beta }(\beta)\end{array}$ & $\mathrm{t}$ & $\mathrm{p}$ & $\begin{array}{c}\text { Adjusted } \\
\mathrm{R}^{2 \text { nd }}\end{array}$ & $\mathrm{F}$ \\
\hline (Constant) & 8.279 & 2.280 & - & 15.175 & 0.000 & - & - \\
Alexithymia & 0.273 & 0.101 & 0.094 & -2.701 & 0.007 & 0.12 & 7.293 \\
Time spent on conversation & 6.090 & 0.715 & 0.285 & 8.521 & 0.000 & 0.09 & 20.173 \\
\hline
\end{tabular}

Dependent Variable: Ruminative Thought

Table 4. Relationship between participant characteristics and scale and sub-dimension scores

\begin{tabular}{|c|c|c|c|c|c|c|c|c|c|c|}
\hline & \multicolumn{2}{|c|}{$\begin{array}{l}\text { Alexithymia } \\
\text { total }\end{array}$} & \multicolumn{2}{|c|}{$\begin{array}{l}\text { "Difficulty iden- } \\
\text { tifying feelings" }\end{array}$} & \multicolumn{2}{|c|}{$\begin{array}{l}\text { "Difficulty descri- } \\
\text { bing feelings" }\end{array}$} & \multicolumn{2}{|c|}{$\begin{array}{l}\text { "Externally orien- } \\
\text { ted thinking" }\end{array}$} & \multicolumn{2}{|c|}{$\begin{array}{l}\text { Ruminative } \\
\text { Thinking }\end{array}$} \\
\hline & $\mathrm{r}^{\mathrm{a}}$ & $\mathrm{p}$ value & $\mathrm{r}^{\mathrm{a}}$ & $\mathrm{p}$ value & $\mathrm{r}^{\mathrm{a}}$ & $\mathrm{p}$ value & $\mathrm{r}^{\mathrm{a}}$ & $\mathrm{p}$ value & $\mathrm{r}^{\mathrm{a}}$ & $\mathrm{p}$ value \\
\hline Age & -0.053 & 0.125 & 0.060 & 0.085 & 0.031 & 0.373 & 0.051 & 0.146 & -0.060 & 0.085 \\
\hline $\begin{array}{l}\text { Time spent on conversation } \\
\text { throughout the day }\end{array}$ & -0.097 & 0.007 & -0.081 & 0.020 & -0.082 & 0.019 & -0.094 & 0.007 & 0.286 & 0.000 \\
\hline $\begin{array}{l}\text { Amount of cigarettes } \\
\text { smoked daily }\end{array}$ & 0.286 & 0.000 & 0.045 & 0.200 & 0.062 & 0.076 & 0.057 & 0.103 & 0.002 & 0.972 \\
\hline $\begin{array}{l}\text { Number of people } \\
\text { living together }\end{array}$ & -0.015 & 0.000 & -0.070 & 0.000 & -0.093 & 0.000 & -0.091 & 0.000 & -0.179 & 0.003 \\
\hline
\end{tabular}

$\mathrm{p}<0.05 ; \quad \mathrm{r}^{\mathrm{a}}$ Pearson correlation test was used

Multiple regression analysis of variables that affect the ruminative thinking levels of individuals was performed. In the advanced analysis, it was observed that the level of ruminative thinking of the people was affected by the level of alexithymia by $12 \%$ and from the time spent for conversation by $9 \%$ (Table 3 ).

\section{Relationship between ruminative thinking and instrumentality and subdimensions}

Ruminative Thought Style Questionnaire and Toronto Alexithymia Scale $(\mathrm{r}=0.094, \mathrm{p}=0.007)$ and its subdimensions (Difficulty recognizing their feelings; $r=0.081$, $\mathrm{p}=0.020$; Difficulty expressing feelings, $\mathrm{r}=0.082$, $\mathrm{p}=0.019$; Expressive thought $\mathrm{r}=0.091, \mathrm{p}=0.009$ ) a positive and significant relationship was determined between (Table 2).

\section{With ruminative thinking, tool oxidation and the subdimensions sociodemographic relationship between properties}

A negative statistically significant relationship was found between the time people spend for conversation and the number of people living together, and the Ruminative Thought Style Questionnaire, the Toronto Alexithymia Scale, and its sub-dimensions $(\mathrm{p}<0.05)$ (Table 4).
Comparing the characteristic features and scale scores of individuals, the Ruminative Thought Style Questionnaire, Toronto Alexithymia Scale and difficulty in expressing emotions and difficulty in recognizing their emotions subscale scores were statistically significantly lower than those of living with family/friends and those who lived alone and those with good communication in relationships were significantly lower than those with bad ones $(\mathrm{p}<0.05)$ (Table 5).

The Ruminative Thought Style Questionnaire, Toronto Alexithymia Scale and subscale scores of those who had COVID-19 themselves or their family/relatives were found to be statistically significantly higher than those who did not have COVID-19 themselves or their family/relatives $(\mathrm{p}<0.05)$. In addition, it was determined that gender and income level did not affect the levels of ruminative thinking and alexithymia of individuals (p>0.05) (Table 5).

\section{DISCUSSION}

In this study, it was aimed to determine the rumination and alexithymia levels of individuals in the COVID-19 pandemic process in the general population. In this study, which is the first research to evaluate 
rumination and alexithymia, the levels of ruminative thought and alexithymia of individuals were found high during the pandemic process. In the literature, it was determined that individuals showed alexithymic properties during the COVID-19 pandemic process (Tang et al. 2020). Rumination is often accompanied by depression and anxiety (Kertz et al. 2015). Alexithymia is directly related to depression (Gunther et al. 2016). Factors such as not leaving the house, change in daily life, fear of disease in the pandemic process create stress and anxiety in people and psychiatric disorders are more common (Peteet 2020). From this point of view, the high levels of rumination and alexithymia in individuals is expected.

In our study, a positive correlation was observed between rumination and alexithymia. Rumination, which is the state of thinking the same things over and over again by focusing on distressing situations, and alexithymia, which means difficulties in defining and expressing emotions and it is expected to find a relationship between, but as far as we know, this study is the first to show this relationship (Brinker et al 2013,
Luminet et al. 2018). This relationship is probably twofold and can put the person in a negative loop. In this study, it was found that rumination is profoundly affected by alexithymia. Examination of alexithymia in patients with rumination and whether or not rumination is present in patients with alexithymia allows to analyse people better and plan interventions.

Living alone has shown to increase depressive symptoms (Stahl et al. 2017). In our study, it was found that rumination and alexithymia, which are predictors of depression, are more common in those living alone than those living with family/friends. In addition, the long time spent for conversation during the day and the good communication in relationships were found to be negatively related to rumination and alexithymia. Antivirus measures, especially the social distance rule, causes people to spend less time in conversation and less in social environments during the day. In order to prevent the development of psychological disorders, individuals should be advised to continue communicating within the framework of social distance rules.

Table 5. Participant characteristics and scale score comparison

\begin{tabular}{|c|c|c|c|c|c|}
\hline Sex & $\begin{array}{c}\text { Female } \\
\text { Mean } \pm \text { SD }\end{array}$ & $\begin{array}{c}\text { Male } \\
\text { Mean } \pm \text { SD }\end{array}$ & $\begin{array}{c}\text { Test value } \\
\mathrm{Z}^{\mathrm{a}} \\
\end{array}$ & $\mathrm{p}$ value & \\
\hline Ruminative Thinking & $90.64 \pm 1.53$ & $94.04 \pm 38.44$ & -0.941 & 0.374 & \\
\hline Alexithymia total & $72.23 \pm 13.36$ & $71.37 \pm 13.99$ & -0.982 & 0.326 & \\
\hline "Difficulty identifying feelings" & $24.72 \pm 5.02$ & $24.32 \pm 5.37$ & -0.953 & 0.341 & \\
\hline "Difficulty describing feelings" & $17.87 \pm 3.99$ & $17.60 \pm 4.23$ & -1.059 & 0.290 & \\
\hline "Externally oriented thinking" & $29.63 \pm 5.72$ & $29.44 \pm 5.76$ & -0.456 & 0.648 & \\
\hline Who he/she lives with & Alone & Family/friend & $\mathrm{Z}^{\mathrm{a}}$ & $\mathrm{P}$ & \\
\hline Ruminative Thinking & $95.70 \pm 37.47$ & $89.36 \pm 43.56$ & -2.627 & 0.009 & \\
\hline Alexithymia total & $68.41 \pm 14.10$ & $70.52 \pm 12.85$ & -2.110 & 0.035 & \\
\hline "Difficulty identifying feelings" & $23.76 \pm 5.35$ & $24.01 \pm 4.92$ & -2.169 & 0.030 & \\
\hline "Difficulty describing feelings" & $17.91 \pm 4.12$ & $17.36 \pm 4.12$ & -1.999 & 0.041 & \\
\hline "Externally oriented thinking" & $29.73 \pm 5.94$ & $29.14 \pm 5.32$ & -1.793 & 0.073 & \\
\hline Income Level & Good & $\mathrm{Bad}$ & Medium & $\begin{array}{l}\text { Test value } \\
\text { KWX }^{\mathrm{b}}\end{array}$ & p-value \\
\hline Ruminative Thinking & $85.51 \pm 42.71$ & $95.73 \pm 37.16$ & $93.16 \pm 39.89$ & 3.445 & 0.179 \\
\hline Alexithymia total & $71.73 \pm 14.19$ & $72.68 \pm 13.70$ & $71.48 \pm 13.60$ & 1.339 & 0.512 \\
\hline "Difficulty identifying feelings" & $24.48 \pm 5.32$ & $24.85 \pm 5.19$ & $24.40 \pm 5.20$ & 1.297 & 0.523 \\
\hline "Difficulty describing feelings" & $17.86 \pm 4.32$ & $18.04 \pm 4.08$ & $17.59 \pm 4.09$ & 2.397 & 0.302 \\
\hline "Externally oriented thinking" & $29.38 \pm 5.96$ & $29.78 \pm 5.81$ & $29.49 \pm 5.67$ & 0.825 & 0.662 \\
\hline Communication in relationships & Good & Poor & I do not know & $\begin{array}{l}\text { Test value } \\
\mathrm{KWX}^{\mathrm{b}}\end{array}$ & p-value \\
\hline Ruminative Thinking ${ }^{\mathrm{c}}$ & $48.70 \pm 26.27^{\mathrm{c}}$ & $121 \pm 11.28$ & $119 \pm 13.98$ & 584.176 & 0.000 \\
\hline Alexithymia total $^{\mathrm{c}}$ & $29.68 \pm 6.13^{\mathrm{c}}$ & $71.33 \pm 13.46$ & $71.66 \pm 12.74$ & 1.256 & 0.039 \\
\hline "Difficulty identifying feelings"c & $14.71 \pm 4.43^{\mathrm{c}}$ & $24.31 \pm 5.12$ & $24.44 \pm 5.03$ & 1.526 & 0.036 \\
\hline "Difficulty describing feelings" & $17.80 \pm 4.36$ & $17.58 \pm 4.12$ & $17.78 \pm 3.79$ & 0.571 & 0.502 \\
\hline "Externally oriented thinking" & $29.68 \pm 6.13$ & $29.42 \pm 5.69$ & $29.44 \pm 5.20$ & 0.962 & 0.618 \\
\hline Infection with COVID-19 & His/Herself & Family/Relative & Nobody & $\begin{array}{l}\text { Test value } \\
\mathrm{KWX}^{\mathrm{b}}\end{array}$ & p-value \\
\hline Ruminative Thinking ${ }^{\mathrm{c}}$ & $139.86 \pm 0.34$ & $115 \pm 115.56$ & $89.89 \pm 19.31^{\mathrm{c}}$ & 584.08 & 0.000 \\
\hline Alexithymia total $^{\mathrm{c}}$ & $70.89 \pm 13.34$ & $71.27 \pm 13.23$ & $59.68 \pm 10.20^{c}$ & 1.256 & 0.037 \\
\hline "Difficulty identifying feelings"c & $24.62 \pm 5.09$ & $24.29 \pm 5.11$ & $17.59 \pm 3.98^{c}$ & 1.417 & 0.021 \\
\hline "Difficulty describing feelings" c & $17.24 \pm 3.91$ & $17.59 \pm 3.98$ & $18.04 \pm 4.43^{\mathrm{c}}$ & 1.612 & 0.025 \\
\hline "Externally oriented thinking" & $29.02 \pm 5.60$ & $29.33 \pm 5.58$ & $25.99 \pm 6.06^{\mathrm{c}}$ & 1.962 & 0.018 \\
\hline
\end{tabular}

\footnotetext{
${ }^{\mathrm{a}}$ The Mann-Whitney U test; ${ }^{\mathrm{b}}$ The Kruskal-Wallis Test; ${ }^{\mathrm{c}}$ Bonferroni correction was performed
} 
Psychopathological symptoms such as depression, anxiety, suicidal thought, post-traumatic stress disorder symptoms, autism-related symptoms, and obsessivecompulsive disorder symptoms have been shown to increase in individuals (Rohde 2020). Symptoms of affective disorder, depression and anxiety are increased in healthcare where the infection is more common, and healthcare workers who are more in contact with infected individuals (Pappa 2020). Infected individuals or their relatives are also expected to show psychopathological symptoms. This study shows that individuals who have had COVID-19 disease, or relatives of individuals who have had COVID-19 disease, have higher levels of ruminative thinking and alexithymia than those who himself or a relative have not encountered COVID-19.

In the study conducted by De Barros et al. (2018) alexithymia score was higher in women than in men. Shors et al. (2017) also stated that ruminative thoughts are seen more frequently in women. In our study, unlike these findings, no difference was found in women and men in terms of ruminative thought and alexithymia. It is thought that this may be due to the gender groups having the same concerns in the pandemic process.

In a study conducted by Emery et al. (2020) a negative relationship was found between age and negative rumination. Because age is a risk factor for infection in the pandemic process, older individuals have more stress factors and need to take more precautions. (American Geriatrics Society 2020, Landi et al. 2020). In this study conducted in the pandemic process, the age and rumination levels decreased in previous studies were not observed (Sutterlin et al. 2012, Ricarte et al. 2016). It is thought that this may be related to severe disease and mortality rates in COVID-19 disease in the geriatric population compared to the young population.

In the study conducted by Penacoba Puente et al. (2013) a positive relationship was found between age and alexithymia. Other studies have supported this finding (Mattila et al. 2006, Paradiso et al. 2008). In this study, no relation was found between age and alexithymia. It is thought that this situation can be explained by the fact that the average age of the elderly population participating in the study is not too high, the majority of them live with family or friends and their communication skills are good.

In a study, it was stated that rumination is associated with economic disadvantage (Zvolensky et al. 2018). Also, higher-income is associated with lower alexithymia (Han et al. 2012). In a study conducted in the 7-8. month after isolation in the SARS-CoV-1 virus epidemic, the most important predictor of the psychological disorders of individuals was determined as income level (Mihashi et al. 2009). On the other hand, there was no relationship between income level and rumination and alexithymia in our study.

\section{CONCLUSION}

In the context of these limitations, it was found that individuals had high alexithymia and rumination levels during the COVID-19 pandemic process. It was found that alexithymia levels of individuals affect and explain the rumination levels to a large extent.

This study has contributed to past research and is the first study to show a relationship between rumination and alexithymia. The results suggest that more psychological problems may arise in individuals after the COVID-19 pandemic.

In the process of the COVID-19 pandemic, individuals can show psychopathological features. In this period when individuals are forced to live a lonely life, healthcare professionals should be careful against alexithymia and rumination that can be seen in individuals. Psychological intervention programs can be developed to protect public health. People can be directed to online conversations to recognize and express their feelings. Exercises to reduce rumination can be recommended. More comprehensive studies are needed in the field of alexithymia and rumination.

\section{Limitations}

The study has many limitations. First, the crosssectional design limited the ability to make inferences about the directions of causality. More significant results could be obtained with data from more cities and countries. Secondly, although scales with validity and reliability were used to determine alexithymia and rumination levels of individuals, no measurement was performed in the presence of an expert. Since the study was conducted during the quarantine applications, individuals filled in the scale questions via the online questionnaire. Third, there are many factors affecting alexithymia and rumination, and these have not been evaluated. There is a need for studies where face to face sessions are held when there are no social isolation rules and various factors are evaluated

\section{Acknowledgements: None. Authorship statement:}

The authors have confirmed that all of the authors meet the IC-MJE criteria for authorship credit (www.icmje.org/ethical_1author.html), as follows:

Elif Yuldirtm Ayaz \& Berna Dincer making substantial contributions to the conception or design of the work, data collection, data analysis and manuscript writing and drafting the article or revising it critically for important intellectual content.

\section{Conflict of interest: None to declare.}

\section{Contribution of individual authors:}

All authors reviewed and discussed the manuscript draft and contributed to the final manuscript and all authors give final approval of the version to be submitted. 


\section{References}

1. Aktug ZB, Iri R, Aktug Demir N: COVID-19 immune system and exercise. Journal of Human Sciences 2020; 17:513-520. https://doi.org/10.14687/jhs.v17i2.6005

2. American Geriatrics Society. American Geriatrics Society (AGS) Policy Brief: COVID-19 and Assisted Living Facilities. Journal of the American Geriatrics Society 2020

3. Bagby M, Taylor GJ, Ryan D: Toronto Alexithymia Scale: Relationship with personality and psychopathology measures. Psychotherapy and Psychosomatics 1986; 45:207-215

4. Beyens I, Frison E, Eggermont S: "I don't want to miss a thing": Adolescents' fear of missing out and its relationship to adolescents' social needs, Facebook use, and Facebook related stress. Computers in Human Behavior 2016; 64:1-8. https://doi.org/10.1016/j.chb.2016.05.083

5. Brinker JK, Campisi M, Gibbs L, Izzard R: Rumination, mood and cognitive performance. Psychology 2013; 04:224-231. https://doi.org/10.4236/psych.2013.43a034

6. Brinker JK \& Dozois DJ: Ruminative thought style and depressed mood. Journal of clinical psychology 2009; 65:1-19

7. Brooks SK, Webster RK, Smith LE, Woodland L, Wessely $S$, Greenberg N, Rubin GJ: The psychological impact of quarantine and how to reduce it: rapid review of the evidence. The Lancet 2020; 395:912-920. https://doi.org/10.1016/S0140-6736(20)30460-8

8. Caretti V, Porcelli P, Solano L, Schimmenti A, Bagby RM, Taylor GJ: Reliability and validity of the Toronto Structured Interview for Alexithymia in a mixed clinical and nonclinical sample from Italy. Psychiatry Research 2011; 187:432-436. https://doi.org/10.1016/j.psychres.2011.02.015

9. Ćosić K, Popović S, Šarlija M, Kesedžić I: Impact of human disasters and COVID-19 pandemic on mental health: Potential of digital psychiatry. Psychiatr Danub 2020; 32:25-31

10. de Barros ACS, Furlan AER, Marques LHN, de Araújo Filho GM: Gender differences in prevalence of psychiatric disorders, levels of alexithymia, and coping strategies in patients with refractory mesial temporal epilepsy and comorbid psychogenic nonepileptic seizures. Epilepsy and Behavior 2018; 82: 1-5. https://doi.org/10.1016/j.yebeh.2018.02.026

11. Gao J, Zheng P, Jia Y, Chen H, Mao Y, Chen Set al.: Mental health problems and social media exposure during COVID-19 outbreak. Plos one 2020; 15: e0231924

12. Gulec H, Kose S, Gulec MY, Citak S, Evren C, Borckardt $J$, Sayar K: Reliability and factorial validity of the Turkish version of the 20-item Toronto alexithymia scale (TAS-20). Klinik Psikofarmakoloji Bulteni 2009; 19:214

13. Gunther V, Rufer M, Kersting A, Suslow T: Predicting symptoms in major depression after inpatient treatment: The role of alexithymia. Nordic Journal of Psychiatry 2016; 70:392398. https://doi.org/10.3109/08039488.2016.1146796

14. Han D, Zhang Y, Li B, Lv Z, Huo X, Li Y, Zhong Y: Alexithymia in Chinese chronic obstructive pulmonary disease (COPD) patients: The prevalence and related factors of alexithymia. Psychiatry Research 2012; 198:274278. https://doi.org/10.1016/j.psychres.2011.10.018

15. Hendryx MS, Haviland MG, Shaw DG: Dimensions of Alexithymia and their relationships to anxiety and depression. Journal of Personality Assessment 1991; 56. 227-237. https://doi.org/10.1207/s15327752jpa5602_4

16. Huang L, Xu FM, Liu HR: Emotional responses and coping strategies of nurses and nursing college students during COVID-19 outbreak. In medRxiv. Cold Spring Harbor Laboratory Press, 2020.

https://doi.org/10.1101/2020.03.05.20031898

17. Jakovljevic M, Bjedov S, Jaksic N, Jakovljevic I: COVID19 pandemia and public and global mental health from the perspective of global health security. Psychiatr Danub 2020; 32:6-14

18. Karatepe HT, Yavuz FK, Turkcan A: Validity and reliability of the Turkish version of the ruminative thought style questionnaire. Klinik Psikofarmakoloji Bülteni-Bulletin of Clinical Psychopharmacology 2013; 23:231-241

19. Karsikaya S, Kavakci O, Kugu N, Guler AS: Migren hastalarnda travma sonras? stres bozuklugu: Migren, travma ve aleksitimi. Noropsikiyatri Arsivi 2013; 50:263268. https://doi.org/10.4274/npa.y6611

20. Kertz SJ, Koran J, Stevens KT, Björgvinsson T: Repetitive negative thinking predicts depression and anxiety symptom improvement during brief cognitive behavioral therapy. Behaviour Research and Therapy 2015; 68:54-63. https://doi.org/10.1016/j.brat.2015.03.006

21. Landi F, Barillaro C, Bellieni A, Brandi VA, Carf? C, Cipriani et al.: The geriatrician: the frontline specialist in the treatment of COVID-19 patients. Journal of the American Medical Directors Association 2020; 21: 937-938

22. Emery L, Sorrell A, Miles C: Age Differences in Negative, but not Positive, Rumination. The Journals of Gerontology: Series B. 2020; 75:80-84. https://doi.org/10.1080/1059924X.2017.1319315

23. Luminet O, Bagby RM, Taylor GJ (Eds.): Alexithymia: Advances in research, theory, and clinical practice. Cambridge University Press, 2018

24. Marčinko D, Jakovljević M, Jakšić N, Bjedov S, Mindoljevic Drakulić A: The importance of psychodynamic approach during COVID-19 pandemic. Psychiatr Danub 2020; $32: 15-21$

25. Mihashi M, Otsubo Y, Yinjuan X, Nagatomi K, Hoshiko M, Ishitake T: Predictive factors of psychological disorder development during recovery following SARS outbreak. Health Psychology?: Official Journal of the Division of Health Psychology, American Psychological Association 2009; 28:91. https://doi.org/10.1037/A0013674

26. Mattila AK, Salminen JK, Nummi T, Joukamaa M: Age is strongly associated with alexithymia in the general population. Journal of Psychosomatic Research 2006; 61: 629-635. https://doi.org/10.1016/j.jpsychores.2006.04.013

27. Nolen-Hoeksema S, Stice E, Wade E, Bohon C: Reciprocal relations between rumination and bulimic, substance abuse, and depressive symptoms in female adolescents. Journal of Abnormal Psychology, 2007; 116:198-207. https://doi.org/10.1037/0021-843X.116.1.198

28. Pappa S, Ntella V, Giannakas T, Giannakoulis VG, Papoutsi E, Katsaounou P: Prevalence of depression, anxiety, and insomnia among healthcare workers during the COVID-19 pandemic: A systematic review and meta-analysis. Brain, Behavior, and Immunity 2020. https://doi.org/10.1016/j.bbi.2020.05.026

29. Papageorgiou C, Wells A: An empirical test of a clinical metacognitive model of rumination and depression. Cognitive Therapy and Research 2003; 27: 261-273

30. Paradiso S, Vaidya JG, McCormick LM, Jones A, Robinson RG: Aging and alexithymia: Association with reduced right rostral cingulate volume. American Journal of Geriatric Psychiatry 2008; 16:760-769. https://doi.org/10.1097/JGP.0b013e31817e73b0 
31. Penacoba Puente C, Velasco Furlong L, Ecija Gallardo C, Cigaran Mendez M, McKenney K: Anxiety, depression and alexithymia in fibromyalgia: are there any differences according to age?. Journal of Women \& Aging 2013; 25:305-320

32. Peteet JR: COVID-19 Anxiety. Journal of Religion and Health 2020 https://doi.org/10.1007/s10943-020-01041-4

33. Ricarte J, Ros L, Serrano JP, Martínez-Lorca M, Latorre JM: Age differences in rumination and autobiographical retrieval. Aging and Mental Health 2016; 20:1063-1069. https://doi.org/10.1080/13607863.2015.1060944

34. Rohde C, Hougaard Jefsen O, Norremark B, Aalkjor Danielsen A, Ostergaard SD: Psychiatric symptoms related to the COVID-19 pandemic. Acta Neuropsychiatrica 2020; 1-7. https://doi.org/10.1017/neu.2020.24

35. Shors TJ, Millon EM, Chang HYM, Olson RL, Alderman BL: Do sex differences in rumination explain sex differences in depression? In Journal of Neuroscience Research 2017; 95:711-718. https://doi.org/10.1002/jnr.23976

36. Sifneos PE: Affect, emotional conflict, and deficit: an overview. Psychotherapy and psychosomatics 1991; 56:116-122

37. Siyu C, Xia M, Wen W, Cui L, Yang W, Liu S et al.: Mental health status and coping strategy of medical workers in China during The COVID-19 outbreak. In medRxiv. Cold Spring Harbor Laboratory Press, 2020. https://doi.org/10.1101/2020.02.23.20026872

38. Smith JM, Alloy LB: A roadmap to rumination: A review of the definition, assessment, and conceptualization of this multifaceted construct. In Clinical Psychology Review 2009; 29:116-128. https://doi.org/10.1016/j.cpr.2008.10.003

39. Stahl ST, Beach SR, Musa D, Schulz R: Living alone and depression: the modifying role of the perceived neighborhood environment. Aging and Mental Health 2017; 21:10651071. https://doi.org/10.1080/13607863.2016.1191060

40. Sun L, Sun Z, Wu L, Zhu Z, Zhang F, Shang $Z$ et al.: Prevalence and risk factors of acute posttraumatic stress symptoms during the COVID-19 Outbreak in Wuhan, China.2020. https://doi.org/10.1101/2020.03.06.20032425
41. Sutterlin S, Paap MCS, Babic S, Kübler A, Vögele C: Rumination and age: Some things get better. Journal of Aging Research 2012.

https://doi.org/10.1155/2012/267327

42. Tang $W, H u T$, Yang $L, X u J$ : The role of alexithymia in the mental health problems of home-quarantined university students during the COVID-19 pandemic in China. Personality and Individual Differences 2020; 165. https://doi.org/10.1016/j.paid.2020.110131

43. Taylor GJ: Alexithymia: concept, measurement, and implications for treatment. The American Journal of Psychiatry 1984

44. Taylor G: The alexithymia construct: conceptualization, validation, and relationship with basic dimensions of personality. Ew Trends in Experimental \& Clinical 1994. https://psycnet.apa.org/record/1995-09613-001

45. Wang Y, Di Y, Ye J, Wei W: Study on the public psychological states and its related factors during the outbreak of coronavirus disease 2019 (COVID-19) in some regions of China. Psychology, Health \& Medicine 2020; 26:13-22. doi:10.1080/13548506.2020.1746817

46. Westwood H, Kerr-Gaffney J, Stahl D, Tchanturia K: Alexithymia in eating disorders: Systematic review and meta-analyses of studies using the Toronto Alexithymia Scale. In Journal of Psychosomatic Research 2017; 99:66-81. Elsevier Inc. https://doi.org/10.1016/j.jpsychores.2017.06.007

47. World Health Organization: Novel Coronavirus (2019$n$ CoV) technical guidance. Accessed June 22, 2020

48. Worldometer: Retrieved August 4, 2020, from https://www.worldometers.info/coronavirus

49. Zvolensky MJ, Paulus DJ, Bakhshaie J, Garza M, Valdivieso J, Ochoa-Perez $M$ et al.: Anxiety sensitivity and rumination: Transdiagnostic factors involved in the relation between subjective social status and anxiety and depressive symptoms and disorders among economically disadvantaged latinos in primary care. American Journal of Orthopsychiatry 2018; 88:571-581. https://doi.org/10.1037/ort0000307

Correspondence:

Assistant Professor Berna Dincer, RN, PhD

Istanbul Medeniyet University, Health Science Faculty

Cevizli Yerleşkesi, Şehit Hakan Kurban Caddesi, No:44, 34862, Kartal, İstanbul, Turkey

E-mail: berna.dincer@medeniyet.edu.tr 